\title{
BMJ Open Pharmaceutical industry payments and assisted reproduction in Australia: a retrospective observational study
}

\author{
Emily Aspasia Karanges (D) , ${ }^{1,2}$ Conrad Nangla, ${ }^{3}$ Lisa Parker (D) , ${ }^{3}$ Alice Fabbri, ${ }^{4,5}$ \\ Cynthia Farquhar (D) , ${ }^{6}$ Lisa Bero (iD ${ }^{7}$
}

To cite: Karanges EA, Nangla C, Parker L, et al. Pharmaceutical industry payments and assisted reproduction in Australia: a retrospective observational study. BMJ Open 2021;11:e049710. doi:10.1136/ bmjopen-2021-049710

- Prepublication history and additional supplemental material for this paper are available online. To view these files, please visit the journal online. (http://dx.doi.org/10.1136/ bmjopen-2021-049710).

Received 31 January 2021 Accepted 06 August 2021

Check for updates

(C) Author(s) (or their employer(s)) 2021. Re-use permitted under CC BY-NC. No commercial re-use. See rights and permissions. Published by BMJ.

For numbered affiliations see end of article.

Correspondence to

Dr Lisa Bero;

LISA.BER0@CUANSCHUTZ.EDU

\section{ABSTRACT}

Objectives To investigate the extent and nature of pharmaceutical industry payments related to fertility and assisted reproduction in Australia.

Design and setting This retrospective observational study employed four databases compiled from publicly available pharmaceutical industry transparency reports on educational event sponsorship (October 2011-April 2018), payments to healthcare professionals (0ctober 2015-April 2018) and patient group support (January 2013-December 2017). Analyses were restricted to fertility-related payments by two major manufacturers of fertility medicines in Australia: Merck Serono and Merck, Sharp and Dohme (MSD).

Primary and secondary outcome measures Descriptive statistics on fertility-related payments and other transfers of value (counts, total and median costs in Australian dollars) for educational events and to healthcare professionals and patient groups.

Results Between October 2011 and April 2018, Merck Serono and MSD spent \$A4522263 on 970 fertility-related events for healthcare professionals, including doctors, nurses and fertility scientists. 56.8\% (551/970) events were held by fertility clinics and $29.3 \%$ (284/970) by professional medical associations. Between October 2015 and April 2018, Merck Serono spent \$A403800 across 177 payments to 118 fertility healthcare professionals, predominantly for educational event attendance. Recipients included obstetricians and gynaecologists (76.3\% of payments, $135 / 177)$, nurses $(11.3 \%, 20 / 177)$ and embryologists/fertility scientists $(9.6 \%, 17 / 117)$. The highest paid healthcare professionals held leadership positions in major fertility clinics. Merck Serono provided \$A662 850 to fertility-related patient groups for advocacy and education (January 2013-December 2017). Conclusions The pharmaceutical industry sponsored a broad range of fertility clinicians and organisations, including doctors, nurses, embryologists, professional medical organisations, fertility clinics and patient groups. This sponsorship may contribute to the overuse of fertility services.

\section{INTRODUCTION}

The use of assisted reproductive technologies (ARTs) such as in vitro fertilisation (IVF) and intracytoplasmic sperm injection has increased markedly over the last

\section{Strengths and limitations of this study}

This study provides the first comprehensive account of pharmaceutical industry payments across the field of reproductive medicine in Australia.

- Australia's transparency reports (used in this study) on pharmaceutical industry funding provide data on payments to healthcare professionals, medical organisations and patient/advocacy groups.

- The data used in this study capture pharmaceutical industry payments to all healthcare professionals, including, but not limited to, doctors, nurses and embryologists.

- These data do not capture all major manufacturers of infertility pharmaceuticals and medical devices and therefore underestimate total payments.

- Our analysis of pharmaceutical industry payments to the fertility sector was descriptive, and we are unable to draw conclusions about the impact of the payments on clinical practice.

few decades. ${ }^{1-3}$ Once reserved primarily for couples with barriers to natural fertility such as tubal disease and male factor infertility, advances in techniques, safety, availability and affordability have led to greater access to ART. In 2016, approximately $4 \%$ of children born in Australia ${ }^{3}$ and almost $2 \%$ of children born in the $\mathrm{USA}^{4}$ were conceived using ART.

Despite this, ART remains controversial. Success rates are disappointingly low, with live birth rates no more than $30 \%$ per initiated cycle in women $<36$ years old. ${ }^{5}$ Even when successful, treatment is often associated with high emotional and financial cost. ${ }^{6}$ There are also concerns about the commercialisation and commodification of ART and its effects on patient care. ${ }^{7}$ In many countries, ART service delivery is controlled largely by private providers, although government subsidies may be available under certain conditions. This system is particularly striking in Australia, where ART services are almost exclusively delivered by private, commercial providers with a high degree 
of self-regulation. ${ }^{8}$ Australia's public healthcare system provides partial reimbursement for ART treatment in the case of medical infertility, but out-of-pocket expenses are often considerable. Costs may be further increased by the use of adjunctive treatments such as assisted hatching and preimplantation genetic screening, many of which have no or limited evidence of efficacy. ${ }^{9}{ }^{10}$ Overservicing of patients unlikely to benefit from ART and premature treatment of couples with unexplained fertility and a good chance of natural conception have also been identified as problematic across multiple countries, both in terms of costs and patient safety, and may reflect commercial interests negatively impacting patient care. ${ }^{11}$

To date, discussions around conflicts of interest in ART have largely centred around the private model of service delivery, ${ }^{7}$ while pharmaceutical industry sponsorship has received little attention. With the ongoing increases in ART use and several newly approved and subsidised medicines for ART, fertility is a potential global growth area for pharmaceutical companies. While comprehensive data are lacking, previous studies suggest that pharmaceutical industry sponsorship may be common, including payments to fertility specialists, sponsorship of medical education and research funding. ${ }^{12}$ These activities have been associated with poor quality medicine use and higher healthcare costs across a range of medical specialties. ${ }^{13}$ Pharmaceutical industry sponsorship of physician education, and efforts to restrict it, has been debated for decades and remain an enduring issue. ${ }^{14}$

Australian transparency databases provide unique data on pharmaceutical industry payments to the healthcare sector. Medicines Australia, the pharmaceutical industry trade association, requires member companies to publicly report payments to healthcare professionals, medical facilities, professional organisations, patient groups and other third parties. This study uses these reports to provide a comprehensive analysis of the extent and nature of pharmaceutical industry payments in the area of reproductive medicine and fertility in Australia between October 2011 and April 2018.

\section{METHODS}

\section{Data sources}

We obtained data on pharmaceutical industry payments from publicly available transparency reports submitted to Medicines Australia by its member companies (October 2011-April 2018). Reports were downloaded from the Medicines Australia website and consolidated into databases as previously described. ${ }^{15}$ This project employed four databases corresponding to the following Medicines Australia report categories: (1) educational events for healthcare professionals (hereafter 'Educational Events 2011-2015'; October 2011-September 2015), (2) third party meeting sponsorship ('Educational Events 2015-2018'; October 2015-April 2018; these reports replaced the educational events for healthcare professionals category in October 2015), (3) health consumer organisation support ('Patient Group Support'; January 2013-December 2017), and (4) payments to healthcare professionals (October 2015-April 2018). The time period covered by each database includes all available reports at the time of analysis. The features of each database are detailed in table 1 .

Table 1 Description of the databases included in the study

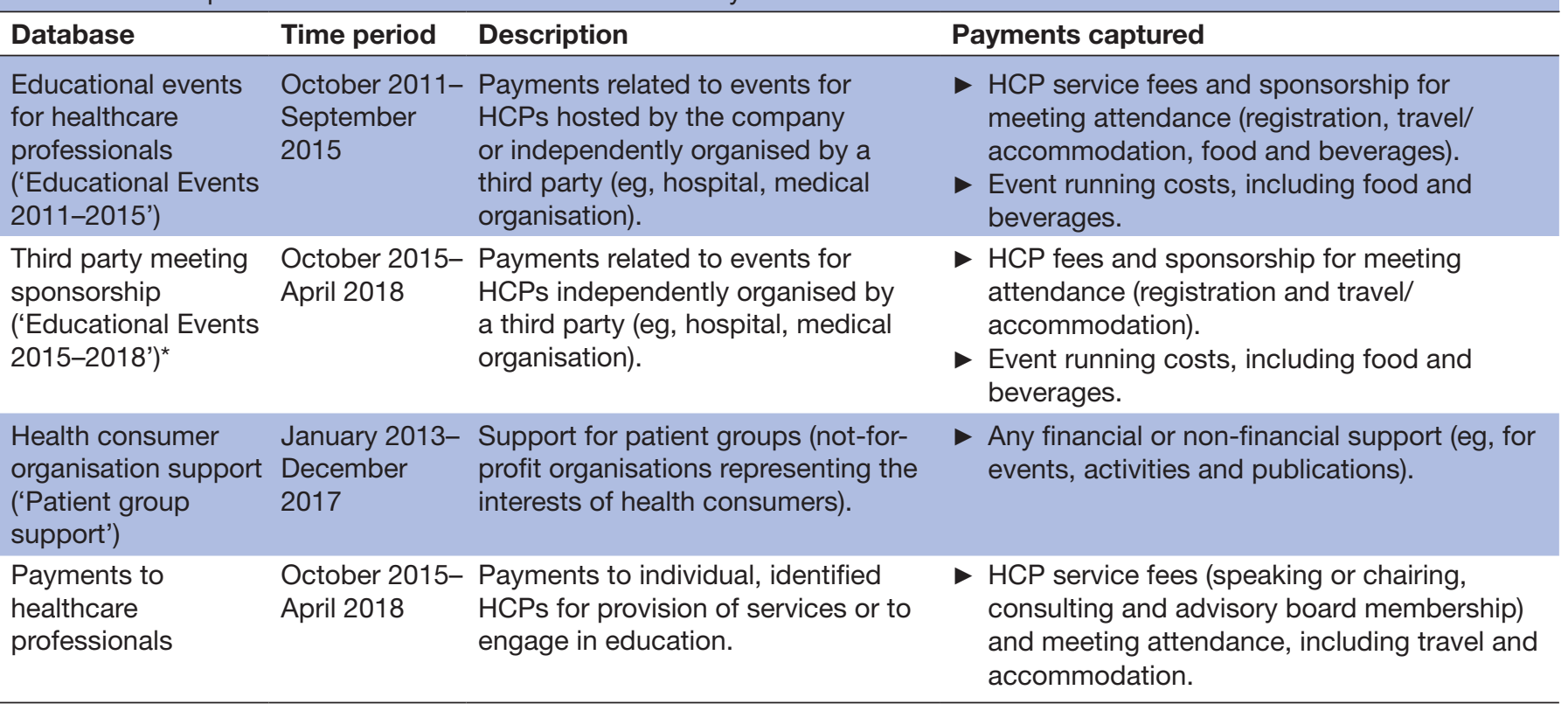

*Replaced 'Educational events for healthcare professionals'. From October 2015, companies were no longer required to disclose spending on company-run educational events and on events were food and beverages where supplied directly by the company (eg, the company brings in sandwiches and drinks or similar modest hospitality), and this is the only means of support.

$\mathrm{HCP}$, healthcare professional. 


\section{Pharmaceutical companies of interest}

We selected our companies of interest by first identifying medicines approved for use in ART (including gonadotrophins, gonadotrophin-releasing hormone (GnRH) agonists, GnRH antagonists, progesterone and clomifene) in Australia using the Australian Medicines Handbook (online) ${ }^{16}$ and NPS MedicineWise. ${ }^{17}$ For each medicine, we determined the manufacturer(s), brands and dates of regulatory approval and subsidy using the Australian Register of Therapeutic Goods and publicly available Pharmaceutical Benefits Advisory Committee Public Summary documents. ${ }^{18}$ Merck Serono, Merck Sharp \& Dohme (MSD) and Ferring Pharmaceuticals emerged as leading suppliers of fertility medicines in Australia, manufacturing multiple products, including medicines approved for use or subsidy during or shortly prior to our period of interest. We excluded manufacturers of medicines approved for use in ART if the companies' main focus was not fertility (eg, Sanofi-Aventis and Novartis) and companies with a broader focus on women's health and contraceptives (Besins Healthcare). We were unable to include Ferring Pharmaceuticals in our analysis as they are not members of Medicines Australia and do not disclose payments. We therefore focused our payment analysis on two companies: Merck Serono and MSD.

\section{Data extraction}

\section{Educational events databases}

We identified fertility-related events in the Educational Events databases by searching event and location descriptions for terms related to ART, using a keyword list iteratively developed by the research team. To ensure complete capture of fertility-related events, we also conducted an online search to identify fertility-related organisations such as clinics, professional medical organisations and patient groups, and incorporated these into our keyword list (see online supplemental table 1).

We used predefined search terms and coding schemes to categorise the type of event (conference, journal club, workshop/training, in-service, lecture tour and clinical/ educational meeting), profession of attending healthcare professionals (eg, medical practitioners, obstetricians and gynaecologists, nurses, fertility nurses, embryologists, etc) and organiser/host of the event (professional medical association, fertility clinic, pharmaceutical company and hospital/health facility). Where the organiser or host was not explicitly identified by the company, we used the event location as a proxy. Unlike the Educational Events 2011-2015 database, the Educational Events 2015-2018 database does not capture events hosted by the pharmaceutical company. It also does not capture company sponsorship of events where food and beverages supplied directly by the company are the only means of their support. ${ }^{19}$ This means our 2015-2018 data are likely an underestimate of total company expenditure on educational events.
We extracted information on the number of fertilityrelated events, total and median cost (in Australian dollars) and number of attendees.

\section{Patient group support database}

We identified fertility-related patient groups using our keyword and patient groups list as above. We extracted the identity of any groups receiving support, the total cost and nature of support.

\section{Payments to healthcare professionals database}

We identified all individuals receiving payments from Merck Serono and MSD, including medical practitioners, nurses and other healthcare professionals (such as pharmacists, psychologists, physiotherapists, etc). We determined the specialty and subspecialty of medical practitioners using the Australian Health Practitioners Regulation Agency's (AHPRA) Register of Practitioners. ${ }^{20}$ We also used the AHPRA Register of Practitioners and online searches to determine the profession and/or specialty of individuals classified as researchers, scientists or unspecified healthcare professionals. Prior to October 2016, healthcare professional consent was required prior to industry disclosure of individual payment details and payments to non-consenting healthcare professionals were reported in aggregate form. We excluded aggregated payments and those totalling $\$ 0(n=2)$.

For Merck Serono, we conducted a keyword search of the primary practice location description to identify payment recipients working in fertility clinics or practices. We were unable to perform this search for MSD as they provided street addresses only. We defined fertility clinicians as: (A) obstetricians and gynaecologists specialising in reproductive endocrinology and infertility or (B) any healthcare professional with a fertility clinic or practice recorded as the primary practice location. To maximise capture of fertility clinicians, we verified the clinical focus of obstetricians and gynaecologists (both Merck Serono and MSD) and all other healthcare professionals (Merck Serono only) not working in fertility clinics using the practice location description and/or an online search for the individual's professional profile. Due to the limited information on location available for MSD and the large number of payment recipients, we were unable to determine the number of fertility clinicians receiving payments from MSD for every profession.

We extracted the reason for payment (meeting attendance, meeting speaker/chairperson, advisory board participation, consultancy and market research) from the company's description of the 'type of service' and 'type of event/activity'. For each profession, we report descriptive statistics on the characteristics of payments, including number of recipients, number and cost of payments (in Australian dollars) and purpose of payment.

\section{Patient and public involvement}

No patients or members of the public were involved in this study. 


\section{RESULTS}

\section{Educational events}

Between October 2011 and April 2018, Merck Serono and MSD spent \$A4522263 on 970 fertility-related events for healthcare professionals, including doctors, nurses and fertility scientists. We present the data on educational events in the two separate time periods that reflect the change in Medicine Australia's reporting requirements.

\section{Period 1 (October 2011-September 2015)}

During the first reporting period, between October 2011 and September 2015, Merck Serono and MSD sponsored 881 fertility-related events, totalling \$3902592 (table 2). Merck Serono had a median spend per event of $\$ 1000$ (IQR: \$300-\$2500), almost three times that of MSD (\$310, IQR: \$133-\$1789).

Fertility-related events accounted for $22.1 \%$ of all events sponsored by Merck Serono and $50.7 \%$ of their total event spend, but only $5.2 \%$ of events and $9.6 \%$ of spending by MSD.

Food and beverages were provided at $84 \%$ of events and were the sole source of spending at over two-thirds (67.4\%) of events. Meeting sponsorship also supported travel, accommodation, service fees and registration costs for speakers and attendees, as well as other event running costs.

In total, there were 23050 individual attendances at fertility-related events (table 2), with a median number of attendees per event of 14 (IQR: 8-27). Fertility clinicians attended $85.8 \%$ of events; these included obstetricians and gynaecologists/specialist fertility doctors $(43.1 \%$ of events), fertility nurses (33.0\%), unspecified fertility clinicians $(25.5 \%)$ and embryologists $(23.3 \%)$.

Fertility-related events were most frequently organised or hosted by fertility clinics $(56.3 \%)$ and professional medical associations (29.1\%). Pharmaceutical companies and hospitals/health facilities each organised less than $5 \%$ of events. The most common types of event were educational/clinical meetings $(41.9 \%)$, journal clubs $(31.6 \%)$ and conferences $(20.3 \%)$.

\section{Period 2 (October 2015-April 2018)}

Following the change in reporting (October 2015-April 2018), Merck Serono and MSD spent $\$ 619671$ across 89 fertility-related events, the majority of which were sponsored by Merck Serono (table 2). MSD sponsored only 13 events with a total cost of $\$ 197477$, but with a median spend per event of \$18636 (\$5000-\$22 000). Merck Serono had a median spend of $\$ 1571$ (IQR: \$1090-\$3577).

Fertility-related events accounted for $47.5 \%$ of all events sponsored by Merck Serono and $59.7 \%$ of total event spend. For MSD, fertility-related events comprised $3.7 \%$ of events and $9.4 \%$ of spending.

Food and beverages were provided at $85 \%$ of fertilityrelated events and were the sole source of spending at $56.2 \%$ of events.

Across both companies, there were 6648 individual attendances at industry-sponsored fertility-related events (table 2). The median number of attendees per event was 120 (IQR: 66-140) for events sponsored by MSD, compared with 23 (IQR: 15-40) for events sponsored by Merck Serono. Overall, the professions attending the highest number of events were medical practitioners $(77.5 \%)$, nurses $(46.1 \%)$ and general practitioners (40.4\%). Fertility clinicians attended $42.6 \%$ of events, with specialist fertility doctors and fertility nurses present at $31.5 \%$ and $16.9 \%$ of events, respectively.

The majority of fertility-related events were organised or hosted by fertility clinics $(61.8 \%)$ or professional medical associations (31.5\%). Events sponsored by Merck Serono were more often hosted by fertility clinics, whereas events by MSD were run by professional medical organisations. Overall, almost three-quarters of fertility-related events were classified as educational/clinical meetings (74.2\%) and $20.2 \%$ as conferences.

\section{Patient group support}

Between January 2013 and December 2017, Merck Serono spent $\$ 662850$ on patient group sponsorship. Spending on fertility-related organisations totalled $\$ 238500$ (36.0\%), with a median yearly spend of $\$ 40000$ (IQR: \$38500-\$60000). The majority of funding (\$203 000) went to Access Australia, Australia's National Infertility Network, to support patient advocacy and support programmes and the production of educational resources. Access Australia disclosed sponsorship by Merck Serono on both their webpage and in their educational resources. In 2017, Merck provided $\$ 5500$ to Fertility Matters, an organisation focused on bringing fertility education into the high school curriculum. Their proposed programme covers fertility issues, fertility preservation, egg and embryo freezing and fertility treatments. ${ }^{21}$

MSD spent $\$ 1144107$ on patient groups between 2013 and 2017 but did not support any fertility-related patient organisations.

\section{Payments to healthcare professionals}

From October 2015 to April 2018, Merck Serono spent $\$ 1748009$ across 701 payments to 473 healthcare professionals and MSD spent $\$ 3073288$ across 2584 payments to 1430 healthcare professionals (table 3 ). Medical practitioners were the primary payment recipients $(63.4 \%$ and $72.4 \%$ of total recipients for Merck Serono and MSD, respectively) and received over three-quarters of total spend $(79.3 \%$ and $85.2 \%$, respectively). Nurses accounted for the majority of the remainder.

Merck Serono spent $\$ 403800$ on fertility clinicians, amounting to $23.1 \%$ of their total spend. Of 118 fertility clinicians receiving payments, $89(75.4 \%)$ were medical practitioners, including 85 obstetricians and gynaecologists; $18(15.3 \%)$ were nurses; and $10(8.5 \%)$ were managers and/or scientists within IVF clinics (eg, including lab managers, scientific directors, embryologists, andrologists and other executives). The median payment received by fertility doctors $(\$ 2006$, IQR: $\$ 1447-\$ 4693$ ) and managers/scientists (\$2032, IQR: 


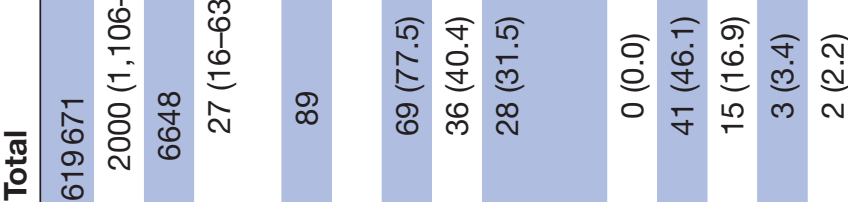

จำ

응

กิ

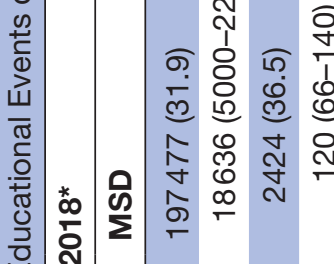

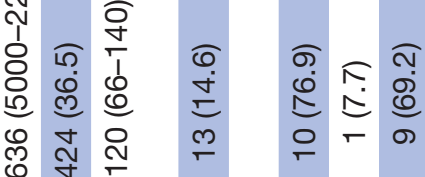

$$
\text { ய․ }
$$

竞

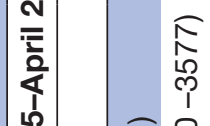

은

을

产

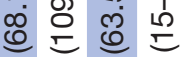

ช

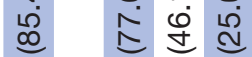

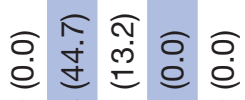

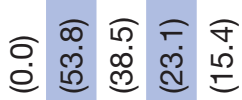

요융 임

다응 0

푱 ठิ

ब्ल

$\mid$

i

당

के

突

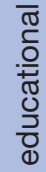

ธิ

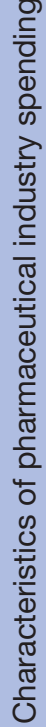
员

న

ชิ

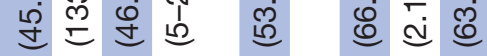

ชิ สิ

- $\sim$ L

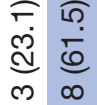

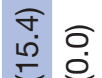

ฮุ่

ọ

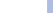

$\sim 0$

으요

๙ ल

@)

กิ 으

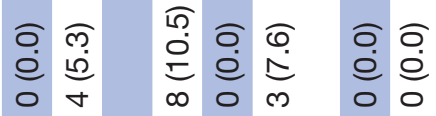

足

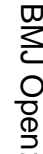

离

응

心

응.

옹

产

$\stackrel{\overrightarrow{0}}{0}$

○

$\stackrel{\omega}{\underline{\omega}}$

?⿳亠口冋

N

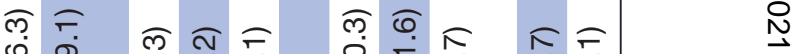

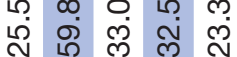

造

守

过

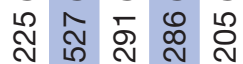

舫

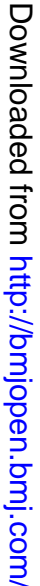

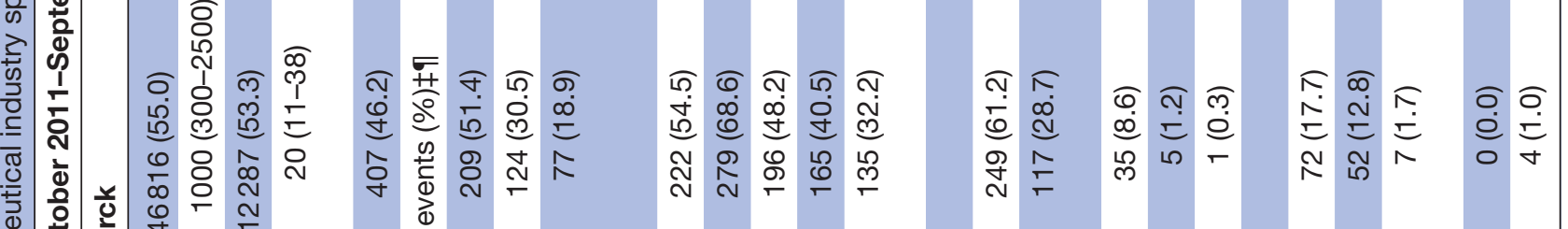

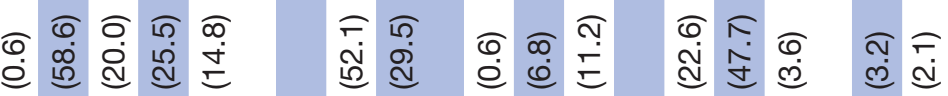

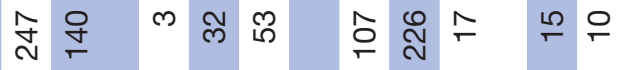

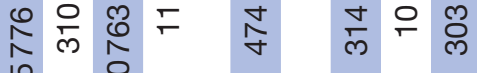

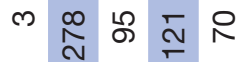

(1)

일.

N

ठั

@

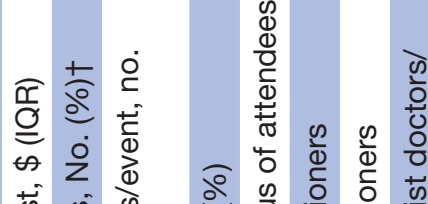

$\frac{2}{5}$

$\frac{\substack{0 \\ \frac{0}{2}}}{\frac{0}{0}}$

呂

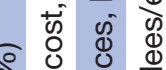

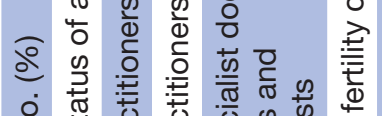

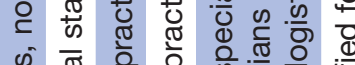

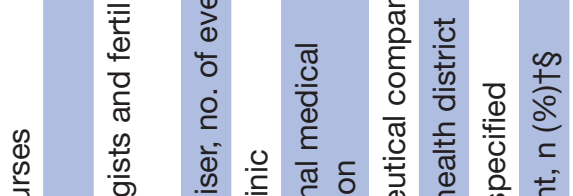

ฟิ

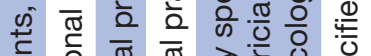

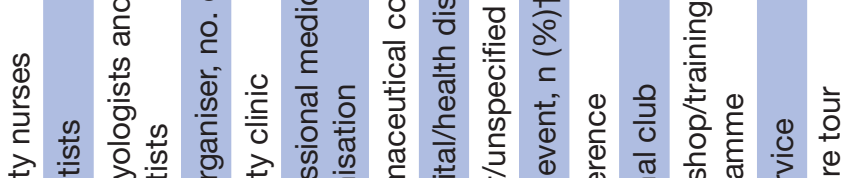

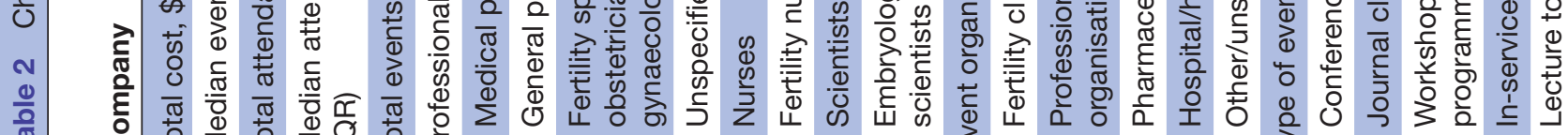

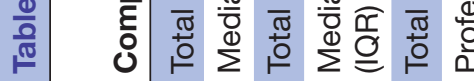

荘

$\approx$

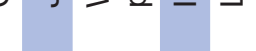




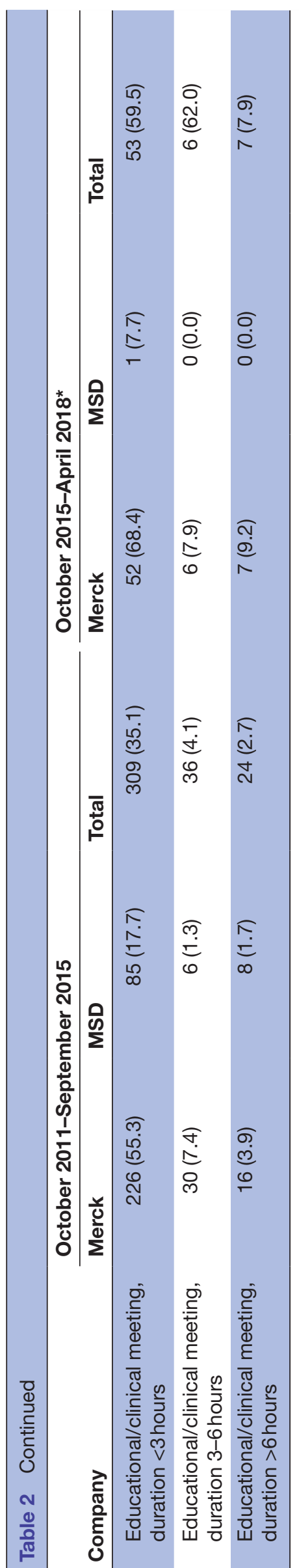

\$1468-\$4855) was approximately twice that of nurses (\$1050, IQR: \$388-\$1892). Of the 177 fertility-related payments by Merck Serono, 152 (85.9\%) were for sponsorship of meeting attendance and $15(8.5 \%)$ for chairing or speaking at meetings; advisory board participation and consulting services comprised less than $3 \%$ of all payments. MSD provided payments to 106 specialist fertility doctors and five embryologists/fertility scientists, together totalling $\$ 204335$ (6.6\% of total spend).

Ten fertility clinicians-nine medical practitioners and one embryologist-received over $\$ 10000$ in payments from either Merck Serono ( $n=7)$ or MSD $(n=4)$; one received over $\$ 10000$ from both companies (total payment $=\$ 28459)$. Eight held leadership positions (director, medical/clinical director and scientific director) in fertility clinics or fertility clinic networks and six held professorial positions, with major roles in medical education, research or professional associations.

\section{DISCUSSION}

Pharmaceutical industry funding of the fertility sector in Australia is considerable and inclusive of a broad range of healthcare professionals as well as clinical, professional and patient organisations. Spending primarily supported healthcare professional education through sponsorship of educational events run by fertility clinics and professional medical associations, and payments to doctors, nurses and laboratory staff for meeting attendance. Although we were not able to analyse the content of these industry-sponsored events, they likely focused on fertility treatments made by the companies, thus promoting their use. ${ }^{22} 23$ Pharmaceutical industry sponsored events have been shown to foster overdiagnosis and overtreatment of various conditions, including depression, osteoporosis and overactive bladder syndrome. ${ }^{24}$

Medical practitioners, particularly obstetricians and gynaecologists, were the primary recipients of payments and were present at the greatest number of educational events, reflecting their role in treatment and prescribing. We also reported frequent inclusion of nurses in pharmaceutical industry activities. Fertility nurses play a key role in patient education, counselling and support across the various stages of ART, as well as medication management and coordination. Moreover, nurses are usually responsible for teaching patients to administer injections for ovulation induction, making them well-placed to influence the uptake of new treatments. ${ }^{25}{ }^{26}$ Notably, all Merck and MSD products receiving regulatory approval or subsidy over the study period were injections indicated for stimulation of ovulation and/or follicular development. With scant evidence for increased live birth rates or superior safety compared with existing products, ${ }^{9}$ factors such as ease of preparation, dosing and administration may play a significant role in driving utilisation. ${ }^{25}$ 


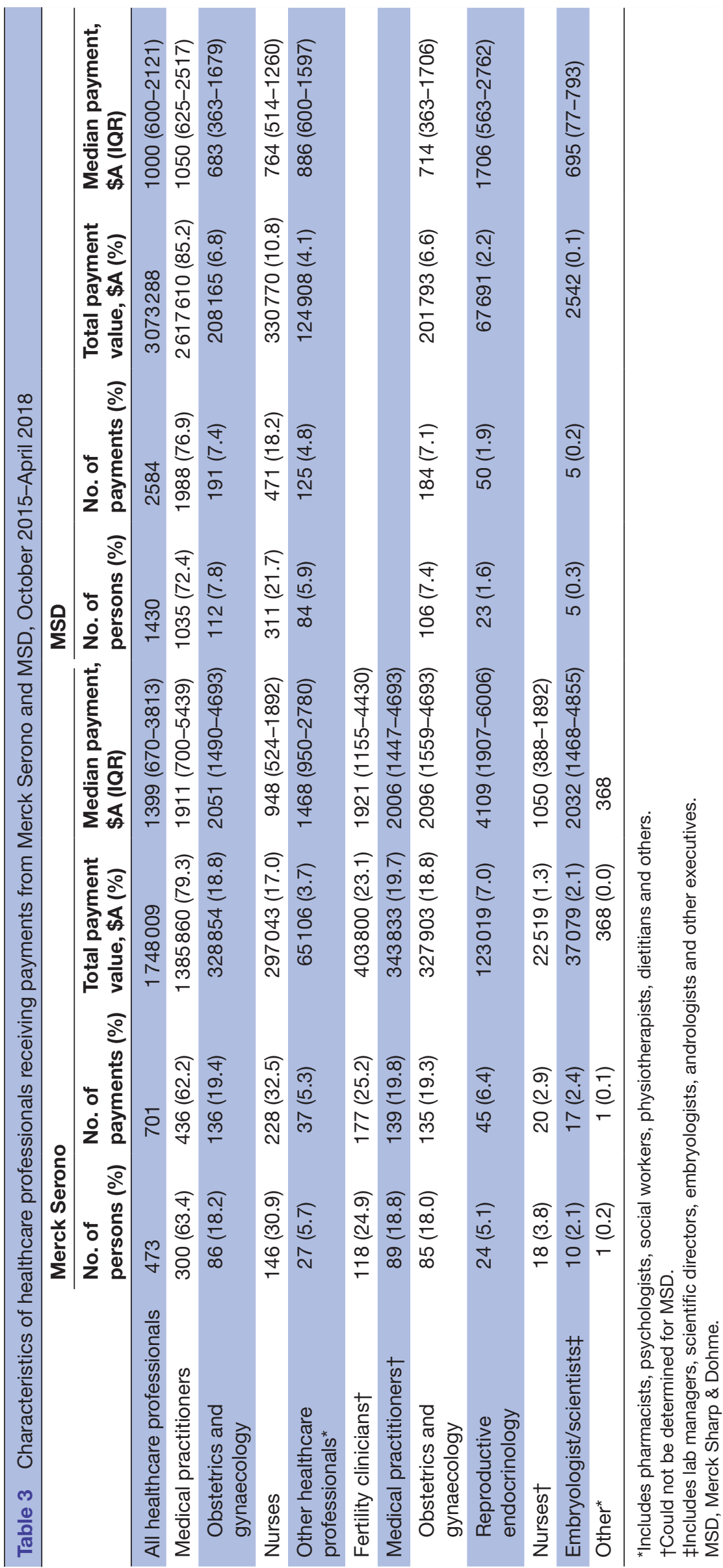


Commercial influences in ART are compounded by interactions between the private fertility clinics and the pharmaceutical industry. More than half of the sponsored educational events in our study were conducted by, through or at private fertility clinics. Moreover, the highest paid individuals were in leadership positions in fertility clinics. Ties between the pharmaceutical industry and fertility clinics have strengthened in recent years, best demonstrated by the 2017 opening of the Merck-Genea Centre of Excellence for Fertility, an education and training facility for ART professionals. ${ }^{27}$ Both the commercial interests of private clinics and the exposure of healthcare professionals to promotional messages at industry-sponsored events may promote overservicing of patients. ${ }^{722248}$ Concerns have been raised about the overuse of ART, including pre-emptive treatment of couples with unexplained infertility, mild endometriosis and mild male factor infertility ${ }^{11}$; overtreatment of older women for whom there is little chance of success ${ }^{29}$; and the unnecessary use of adjuvant treatments with little evidence of efficacy. ${ }^{9} 30$

Finally, our results show that pharmaceutical industry funding extends beyond healthcare professionals to patient and advocacy groups. Patient groups play an influential role in public education, disease awareness, research, clinical guideline development and health advocacy. ${ }^{31}$ Previous studies have shown that groups receiving pharmaceutical industry funding tend to hold clinical or policy positions that align with those of the sponsor. ${ }^{32}$ As a powerful voice in influencing decisions around drug subsidy and pharmaceutical policy, patient groups can greatly influence uptake of a new medicine. ${ }^{33}$ Notably, ACCESS Australia's National Infertility Network, who received over $\$ 200000$ from Merck over the 5-year study period, provided advice supporting Merck's applications for subsidy of Luveris (lutropin alfa, a recombinant luteinising hormone) and Pergoveris (follitropin alfa, a recombinant follicle stimulating hormone, and lutropin alfa) in $2015 .{ }^{3435}$ This was Merck's third attempt at Pergoveris subsidy. Both applications were successful.

Global data on pharmaceutical industry payments to fertility clinicians is sparse and does not directly map onto the data presented in our results. In 2014, US fertility clinicians received a total of US\$3 051463 (\$A4 137970) from industry (including pharmaceutical and medical device companies) with a median of US\$216 (\$A292) per clinician. ${ }^{36}$ Acknowledging the difficulties of immediate comparison, our 2015-2018 results suggest Australian fertility clinicians may receive a lower combined annual total compared with their American counterparts but higher individual annual payments. Data on the 'high receivers' is also difficult to compare but presented here for completeness and reader interest: 2015 data showed the biggest annual pharmaceutical industry payment to an individual fertility specialist in the UK was $£ 20000$ (\$A36253) and $€ 15850$ (\$A9458) in the Netherlands. ${ }^{12}$ An individualised search of Propublica data showed that one US fertility specialist received US $\$ 23147$ (\$A31217) in 2018. ${ }^{37}$ Our data show the highest paid individual clinician in Australia received \$A28 459 from Merck and MSD in the 2.5 years of our data collection period.

\section{Strengths and weaknesses}

This study provides the first comprehensive account of pharmaceutical industry payments across the fertility sector in Australia, capturing payments to a range of healthcare professionals (including physicians, nurses, embryologists, etc) and healthcare organisations. However, our data are limited to member companies of Medicines Australia; they do not capture all major manufacturers of infertility pharmaceuticals or manufacturers of IVF solutions and medical devices. Our results likely underestimate total payments. Some fertility-related payments may have been missed due to limited detail in event descriptions and omission of company-run events from the Educational Events 2015-2018 database. ${ }^{19}$ Our data on payments to healthcare professionals do not specify the product or therapeutic area associated with the payment; therefore, we were unable to identify fertility-related payments to healthcare professionals not affiliated with a fertility centre. We were also unable to draw conclusions about the impact of payments on clinical practice. Further research linking payments to service delivery at the individual practitioner level would strengthen our findings.

\section{CONCLUSIONS}

The pharmaceutical industry contributes considerable funding to the fertility sector. Pharmaceutical industry spending primarily supported healthcare professional education through sponsorship of fertility clinics and professional medical organisations and payments to a broad range of healthcare professionals including doctors, nurses and embryologists. The conflicts of interest created by these payments, together with the commercial influences associated with the private model of service provision, are likely to contribute to the overuse of fertility services. ${ }^{11}$ While conflicts of interest within healthcare are not unique to ART, people undergoing fertility treatments can be considered particularly vulnerable to the drivers of overuse and overtreatment due to the time limited opportunity to conceive. Individuals undergoing fertility treatment should receive care and education from health professionals and patient groups that are free of commercial influence. ${ }^{38}$

\section{Author affiliations}

${ }^{1}$ Centre for Youth Mental Health, The University of Melbourne, Melbourne, Victoria, Australia

${ }^{2}$ Orygen, Parkville, Victoria, Australia

${ }^{3}$ Charles Perkins Centre, School of Pharmacy, Faculty of Medicine and Health, The University of Sydney, Sydney, New South Wales, Australia

${ }^{4}$ Department for Health, University of Bath, Bath, UK 
${ }^{5}$ Centre for Evidence-Based Medicine Odense (CEBMO), Department for Health, University of Southern Denmark, Odense, Denmark

${ }^{6}$ Department of Obstetrics and Gynaecology, University of Auckland, Auckland, New Zealand

${ }^{7}$ Schools of Medicine and Public Health, The University of Colorado Anschutz Medical Center, Denver, Colorado, USA

\section{Twitter Cynthia Farquhar @CindyFarquhar}

Contributors LB conceived the study. All authors contributed to study design. LB, $A F, C N$ and EAK created the databases. CN and EAK wrote the first and subsequent drafts, extracted and analysed the data. LP edited the final draft. All authors critically revised the manuscript and reviewed and approved the final manuscript. $\mathrm{LB}$ is the guarantor.

Funding This project was not funded by a specific grant from any funding agency in the public, commercial or not-for-profit sectors. AF is part of SPECTRUM, a UK Prevention Research Partnership Consortium (MR/S037519/1). UKPRP is an initiative funded by the UK Research and Innovation Councils, the Department of Health and Social Care (England) and the UK devolved administrations and leading health research charities.

Competing interests None declared.

Patient consent for publication Not required.

Ethics approval This study was exempt from ethical review according to the guidelines of The University of Sydney Human Research Ethics Committee and because the data were publicly available.

Provenance and peer review Not commissioned; externally peer reviewed.

Data availability statement Data are available in a public, open access repository. The data underlying this article are publicly available and can be accessed as follows: Educational Events (October 2011 - September 2015), doi: 10.4227/11/592631edbd9d5. Third party meeting sponsorship (October 2015 - October 2018), doi: 10.25910/5d0038d2a439d. Payments to healthcare professionals (October 2015 - October 2018), doi: 10.25910/5d6710d1d3d20. Health consumer group support (January 2013 -December 2016 only), doi: $10.25910 / 5 \mathrm{bc} 67 \mathrm{fed} 51798$. These databases do not include all the variables used in this study. The Australian Health Practitioner Regulation Agency (AHPRA) Register of Practitioners was accessed from: https://www.ahpra.gov.au/Registration/Registersof-Practitioners.aspx?m=Search.

Supplemental material This content has been supplied by the author(s). It has not been vetted by BMJ Publishing Group Limited (BMJ) and may not have been peer-reviewed. Any opinions or recommendations discussed are solely those of the author(s) and are not endorsed by BMJ. BMJ disclaims all liability and responsibility arising from any reliance placed on the content. Where the content includes any translated material, BMJ does not warrant the accuracy and reliability of the translations (including but not limited to local regulations, clinical guidelines, terminology, drug names and drug dosages), and is not responsible for any error and/or omissions arising from translation and adaptation or otherwise.

Open access This is an open access article distributed in accordance with the Creative Commons Attribution Non Commercial (CC BY-NC 4.0) license, which permits others to distribute, remix, adapt, build upon this work non-commercially, and license their derivative works on different terms, provided the original work is properly cited, appropriate credit is given, any changes made indicated, and the use is non-commercial. See: http://creativecommons.org/licenses/by-nc/4.0/.

\section{ORCID iDs}

Emily Aspasia Karanges http://orcid.org/0000-0001-7922-2762

Lisa Parker http://orcid.org/0000-0001-8635-6953

Cynthia Farquhar http://orcid.org/0000-0002-3685-3553

Lisa Bero http://orcid.org/0000-0003-1893-6651

\section{REFERENCES}

1 Ferraretti AP, Nygren K, Andersen AN, et al. Trends over 15 years in ART in Europe: an analysis of 6 million cycles. Hum Reprod Open 2017;2017:hox012.

2 Centers for Disease Control and Prevention, American Society for Reproductive Medicine, Society for Assisted Reproductive Technology. 2016 assisted reproductive technology national summary report. 2018. Atlanta, GA: US Department of Health and Human Services, 2018
3 Fitzgerald O, Paul R, Harris K. Assisted reproductive technology in Australia and New Zealand 2016. Sydney, Australia: National Perinatal Epidemiology and Statistics Unit, The University of New South Wales, 2018.

4 Sunderam S, Kissin DM, Zhang Y, et al. Assisted reproductive technology surveillance - United States, 2016. MMWR Surveill Summ 2019;68:1-23.

5 Newman J, Fitzgerald O, Paul R. Assisted reproductive technology in Australia and New Zealand 2017. Sydney, Australia: National Perinatal Epidemiology and Statistics Unit, University of New South Wales, 2019.

6 National Health and Medical Research Council [NHMRC]. Ethical guidelines on the use of assisted reproductive technology in clinical practice and research. Canberra, Australia: NHMRC, 2017.

7 Blakely B, Williams J, Mayes C, et al. Conflicts of interest in Australia's IVF industry: an empirical analysis and call for action. Hum Fertil 2019;22:230-7.

8 Gorton M. Helping Victorians create families with assisted reproductive treatment: final report of the independent review of assisted reproductive treatment. Melbourne, Australia: State Government of Victoria, 2019.

9 Farquhar C, Marjoribanks J. Assisted reproductive technology: an overview of Cochrane reviews. Cochrane Database Syst Rev 2018;8:CD010537.

10 Heneghan C, Spencer EA, Bobrovitz N, et al. Lack of evidence for interventions offered in UK fertility centres. BMJ 2016;355:i6295.

11 Kamphuis El, Bhattacharya S, van der Veen F, et al. Are we overusing IVF? BMJ 2014;348:g252.

12 Farquhar CM, Vercellini P, Marjoribanks J. Gynaecologists and industry: ain't no sunshine. Hum Reprod 2017;32:1543-8.

13 Fickweiler F, Fickweiler W, Urbach E. Interactions between physicians and the pharmaceutical industry generally and sales representatives specifically and their association with physicians' attitudes and prescribing habits: a systematic review. BMJ Open 2017;7:e016408.

14 Institute of Medicine Committee on Conflict of Interest in Medical Research E, Practice. The National Academies Collection: Reports funded by National Institutes of Health. In: Lo B, Field MJ, eds. Conflict of interest in medical research, education, and practice. Washington, DC: National Academies Press (US), 2009.

15 Parker L, Karanges EA, Bero L. Changes in the type and amount of spending disclosed by Australian pharmaceutical companies: an observational study. BMJ Open 2019;9:e024928.

16 Australian Medicines Handbook Pty Ltd. Australian medicines handbook, 2019. Available: https://amhonline.amh.net.au/ [Accessed 27 Feb 2019].

17 National Prescribing Service. NPS medicine wise. Available: https:// www.nps.org.au [Accessed Feb 2021].

18 Australian Government Department of Health. Public summary documents by product. Available: http://www.pbs.gov.au/info/ industry/listing/elements/pbac-meetings/psd/public-summarydocuments-by-product [Accessed Feb 2019].

19 Medicines Australia. Code of conduct, edition 18. Available: https:// medicinesaustralia.com.au/wp-content/uploads/sites/52/2010/ 01/20150617-PUB-Code-Edition-18-FINAL.pdf [Accessed 20 Dec 2019].

20 Australian Health Practitioner Regulation Agency. Register of practitioners. Available: https://www.ahpra.gov.au [Accessed Jan 2021].

21 Australian Communities Foundation. Fertility matters education package. Available: https://www.communityfoundation.org.au/ proposal/fertility-matters-education-package/ [Accessed 19 Dec 2019].

22 Behdarvand B, Karanges EA, Bero L. Pharmaceutical industry funding of events for healthcare professionals on non-vitamin $\mathrm{K}$ oral anticoagulants in Australia: an observational study. BMJ Open 2019;9:e030253.

23 Yeh JS, Franklin JM, Avorn J, et al. Association of industry payments to physicians with the prescribing of brand-name statins in Massachusetts. JAMA Intern Med 2016;176:763-8.

24 Mintzes B, Swandari S, Fabbri A, et al. Does industry-sponsored education foster overdiagnosis and overtreatment of depression, osteoporosis and over-active bladder syndrome? An Australian cohort study. BMJ Open 2018;8:e019027.

25 Schertz J, Worton $\mathrm{H}$. Nurse evaluation of the redesigned fertility pen injector: a questionnaire-based observational survey. Expert Opin Drug Deliv 2018;15:435-42.

26 Libraro J. The evolving role of the assisted reproduction technology nurse: a contemporary review. In: Gardner DK, Weissman A, Howles $\mathrm{CM}$, et al, eds. Textbook of assisted reproductive techniques, volume 2: clinical perspectives. Boca Raton, FL: Cell Press, 2017: 415-23. 
27 Merck and Genea. Centre of excellence for fertility. Available: https:// www.coefertility.com/eu/ [Accessed Oct 2019].

28 Moynihan R. Key opinion leaders: independent experts or drug representatives in disguise? BMJ 2008;336:1402-3.

29 ESHRE Capri Workshop Group. A prognosis-based approach to infertility: understanding the role of time. Hum Reprod 2017;32:1556-9.

30 Harper J, Jackson E, Sermon K, et al. Adjuncts in the IVF laboratory: where is the evidence for 'add-on' interventions? Hum Reprod 2017;32:485-91.

31 Rose SL, Highland J, Karafa MT, et al. Patient advocacy organizations, industry funding, and conflicts of interest. JAMA Intern Med 2017;177:344-50.

32 Lin DH, Lucas E, Murimi IB, et al. Financial conflicts of interest and the centers for disease control and prevention's 2016 guideline for prescribing opioids for chronic pain. JAMA Intern Med 2017; $177: 427-8$.

33 Lexchin J. Association between commercial funding of Canadian patient groups and their views about funding of medicines: an observational study. PLoS One 2019;14:e0212399.
34 Pharmaceutical Benefits Advisory Committee [PBAC]. Public Summary Document - March 2015 PBAC Meeting. 7.07 Follitropin alfa and lutropin alfa; injection, $150 \mathrm{IU}$ and $75 \mathrm{IU}$, Powder for injection, Vial of solvent, $1 \mathrm{~mL}$ water for injection; Pergoveris ${ }^{\circledR}$, Merck Serono Australia Pty Ltd. Canberra, Australia: Australian Government Department of Health, 2015.

35 Pharmaceutical Benefits Advisory Committee [PBAC]. Public Summary Document - March 2015 PBAC Meeting. 5.15 Lutropin alfa; 75 IU, Powder for injection; Luveris@; Merck Serono Australia Pty Ltd. Canberra, Australia: Australian Government Department of Health, 2015.

36 Tierney NM, Saenz C, McHale M, et al. Industry payments to obstetrician-gynecologists: an analysis of 2014 open payments data. Obstet Gynecol 2016;127:376-82.

37 ProPublica. Available: propublica.org [Accessed Jan 2021].

38 Moynihan R, Macdonald $\mathrm{H}$, Heneghan $\mathrm{C}$, et al. Commercial interests, transparency, and independence: a call for submissions. BMJ 2019;365:11706. 